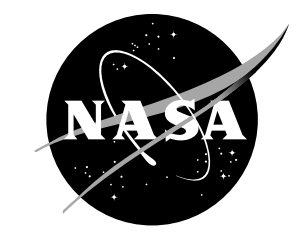

\title{
Numerical Studies of a Supersonic Fluidic Diverter Actuator for Flow Control
}

Suleyman A. Gokoglu, Maria A. Kuczmarski, and Dennis E. Culley Glenn Research Center, Cleveland, Ohio

Surya Raghu

Advanced Fluidics LLC, Columbia, Maryland 


\section{NASA STI Program . . . in Profile}

Since its founding, NASA has been dedicated to the advancement of aeronautics and space science. The NASA Scientific and Technical Information (STI) program plays a key part in helping NASA maintain this important role.

The NASA STI Program operates under the auspices of the Agency Chief Information Officer. It collects, organizes, provides for archiving, and disseminates NASA's STI. The NASA STI program provides access to the NASA Aeronautics and Space Database and its public interface, the NASA Technical Reports Server, thus providing one of the largest collections of aeronautical and space science STI in the world. Results are published in both non-NASA channels and by NASA in the NASA STI Report Series, which includes the following report types:

- TECHNICAL PUBLICATION. Reports of completed research or a major significant phase of research that present the results of NASA programs and include extensive data or theoretical analysis. Includes compilations of significant scientific and technical data and information deemed to be of continuing reference value. NASA counterpart of peer-reviewed formal professional papers but has less stringent limitations on manuscript length and extent of graphic presentations.

- TECHNICAL MEMORANDUM. Scientific and technical findings that are preliminary or of specialized interest, e.g., quick release reports, working papers, and bibliographies that contain minimal annotation. Does not contain extensive analysis.

- CONTRACTOR REPORT. Scientific and technical findings by NASA-sponsored contractors and grantees.
- CONFERENCE PUBLICATION. Collected papers from scientific and technical conferences, symposia, seminars, or other meetings sponsored or cosponsored by NASA.

- SPECIAL PUBLICATION. Scientific, technical, or historical information from NASA programs, projects, and missions, often concerned with subjects having substantial public interest.

- TECHNICAL TRANSLATION. Englishlanguage translations of foreign scientific and technical material pertinent to NASA's mission.

Specialized services also include creating custom thesauri, building customized databases, organizing and publishing research results.

For more information about the NASA STI program, see the following:

- Access the NASA STI program home page at http://www.sti.nasa.gov

- E-mail your question via the Internet to help@ sti.nasa.gov

- Fax your question to the NASA STI Help Desk at $443-757-5803$

- Telephone the NASA STI Help Desk at 443-757-5802

- Write to: NASA Center for AeroSpace Information (CASI) 7115 Standard Drive Hanover, MD 21076-1320 


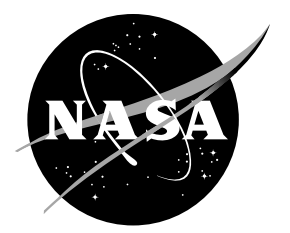

\section{Numerical Studies of a Supersonic Fluidic Diverter Actuator for Flow Control}

Suleyman A. Gokoglu, Maria A. Kuczmarski, and Dennis E. Culley Glenn Research Center, Cleveland, Ohio

Surya Raghu

Advanced Fluidics LLC, Columbia, Maryland

Prepared for the

5th Flow Control Conference

sponsored by the American Institute of Aeronautics and Astronautics Chicago, Illinois, June 28-July 1, 2010

National Aeronautics and

Space Administration

Glenn Research Center

Cleveland, Ohio 44135 


\section{Acknowledgments}

The authors gratefully acknowledge the support of this work by the NASA Fundamental Aeronautics program, Subsonic Fixed Wing project.

This work was sponsored by the Fundamental Aeronautics Program at the NASA Glenn Research Center.

Level of Review: This material has been technically reviewed by technical management.

Available from

NASA Center for Aerospace Information 7115 Standard Drive

Hanover, MD 21076-1320
National Technical Information Service 5301 Shawnee Road Alexandria, VA 22312

Available electronically at http://gltrs.grc.nasa.gov 


\title{
Numerical Studies of a Supersonic Fluidic Diverter Actuator for Flow Control
}

\author{
Suleyman A. Gokoglu, Maria A. Kuczmarski, and Dennis E. Culley \\ National Aeronautics and Space Administration \\ Glenn Research Center \\ Cleveland, Ohio 44135 \\ Surya Raghu \\ Advanced Fluidics LLC \\ Columbia, Maryland 21045
}

\begin{abstract}
The analysis of the internal flow structure and performance of a specific fluidic diverter actuator, previously studied by time-dependent numerical computations for subsonic flow, is extended to include operation with supersonic actuator exit velocities. The understanding will aid in the development of fluidic diverters with minimum pressure losses and advanced designs of flow control actuators. The selfinduced oscillatory behavior of the flow is successfully predicted and the calculated oscillation frequencies with respect to flow rate have excellent agreement with our experimental measurements. The oscillation frequency increases with Mach number, but its dependence on flow rate changes from subsonic to transonic to supersonic regimes. The delay time for the initiation of oscillations depends on the flow rate and the acoustic speed in the gaseous medium for subsonic flow, but is unaffected by the flow rate for supersonic conditions.
\end{abstract}

\subsection{Introduction}

Almost any aerodynamic problem, involving subsonic or supersonic flow, can be mitigated in the laboratory through the proper application of flow control techniques (Ref. 1). In each flow control application, the common denominator is that it requires some type of actuation mechanism. The specific implementation can be passive or active, open-loop or closed-loop; however, with every benefit there is a corresponding penalty when evaluated at the system level. In any practical application, the determining factor in whether to implement flow control at all is in the net effect to the system. Due to this inescapable fact, the actuation mechanism and its ancillary support structure are the determining elements in understanding the penalty aspect of flow control. Nowhere is this more apparent than in internal flow control applications in turbomachinery (Refs. 2 and 3).

The effective and efficient control of supersonic flows by developing simple and robust actuator technologies has been the subject of considerable research in recent years (Refs. 4 to 10). Although relatively successful at lower speeds, many actuators are not very efficient when the primary flow velocities are high.

The ideal actuator for maximizing flow control benefit must develop sufficient control authority (e.g., velocity, momentum, frequency, etc.) at a location which requires the minimum control authority (i.e., where it is most effective). The efficiency of the actuator is a function of the magnitude of the energy transferred to the problematic flow and its spatial extent and direction. For high-speed (Mach number $>1$ ) flow control using some sort of fluidic injection, as in the case of engine inlets for military aircraft, supersonic flow over wings, high-speed jets and shock-boundary layer interactions, this translates to sonic or supersonic exit velocities from the actuator jets. In all these cases, the objective is typically not to alter the freestream flow directly because of the excessive energy requirement, but to leverage, or redistribute, the freestream energy to achieve the desired effect. The size of the actuation device also matters, and its ability to focus energy in a much localized space is perhaps the most important characteristic. 
Passive methods such as ramps and tabs for supersonic flow control bear high penalties, particularly during off-design situations, and may not be effective when the shock is non-stationary. Active flow control devices (whether open or closed-loop) try to minimize the performance penalty by only being activated, and therefore, affecting the flow, during off-design operations. While active devices have the potential for maximizing operational benefits, the total impact is often negated by the added complexity, weight, power, cost, and unreliability to the system. Flow control actuators that approximate the ideal are active devices that minimize these system costs.

Fluidic diverters, as described in this paper and in References 11 to 13, are actively controlled actuators which inject fluid into the freestream in an unsteady, periodic manner. While the devices require a source of pressurized fluid, they have no moving parts, add little to no weight, and require no external power for operation. Furthermore, the devices can be scaled over a great extent in terms of size, periodic frequency, and flow rate, including jet mixing applications for supersonic flows (Ref. 14). Their increasing usage in real applications are being reported more recently, as in such examples of (a) enhancing significantly the performance of a single-element high-lift airfoil by employing a spanwise array of fluidic oscillator jets (Ref. 15), and (b) reducing the drag and increasing the lift substantially of a V-22 airfoil with and without deflected trailing-edge flaps and a semispan V-22 wing/nacelle combination (Ref. 16). In this paper we examine some characteristics of the fluidic diverter when the flow velocities both within and exiting the actuator are supersonic in the hope of extending its applications for the control of supersonic flows.

\subsection{The Fluidic Diverter Actuator}

A schematic of a generic fluidic diverter actuator is shown in Figure 1. The jet created at the end of the converging section is bi-stable in nature and steers to one side of the wall attachment region provided in the chamber due to the Coanda effect (Refs. 17 and 18), the tendency of a fluid jet to stay attached to an adjacent curved surface. A part of the momentum or the pressure pulse is transmitted back through the feedback channel, which switches the jet attachment from one side to the other side of the chamber. Thus, the jet of fluid is diverted alternately into the two outlets provided at the exit.

The frequency characteristics of the actuator greatly depend on the design of the internal geometry of the wall attachment region and the feedback channels. Fluidic oscillators typically have linear flow rate versus frequency characteristics and generally show saturation when sonic conditions are achieved at the converging section. Pulse frequencies from 1 to $10 \mathrm{kHz}$ have been obtained with meso-scale (nozzle sizes in the range of 0.2 to $1 \mathrm{~mm}$ ) fluidic actuators with very low mass flow rates (of the order of 0.05 to $0.5 \mathrm{gm} / \mathrm{s})$.

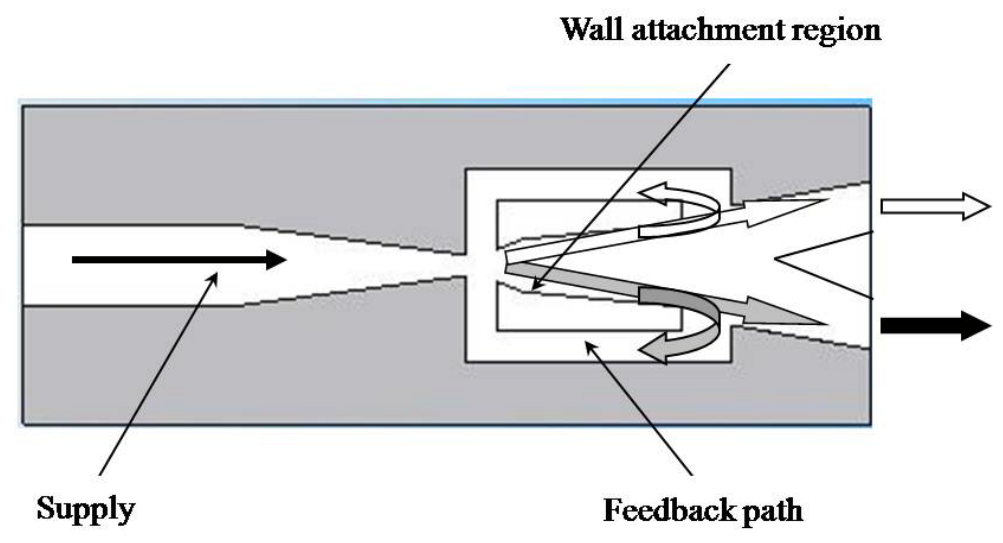

Figure 1.-Schematic of a fluidic diverter actuator. 


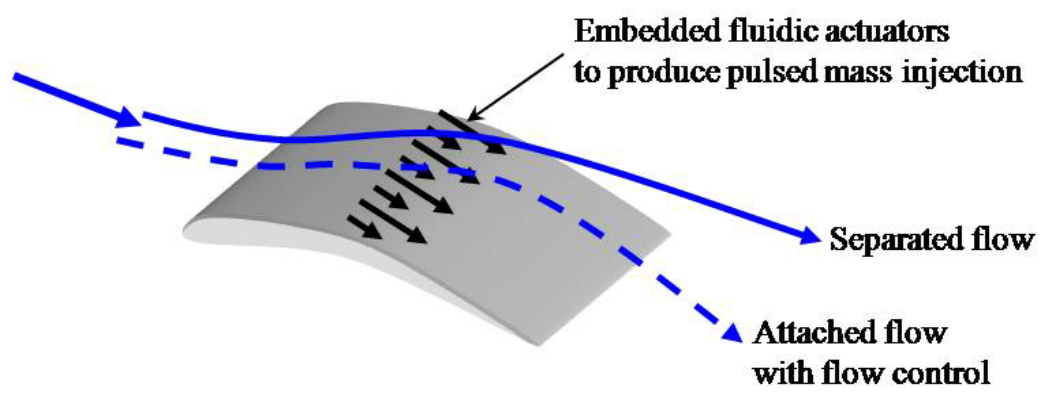

Figure 2.- Separation control using pulsed mass-flow injection with fluidic diverter arrays.

An example of the concept of flow control using such an array of fluidic actuators in a stator vane is shown in Figure 2. Pulsing jets with sufficient authority (velocity amplitude ratio $u / U \sim 1$, where $u$ is the exit velocity from the actuator and $U$ is the freestream velocity) slightly ahead of the separation line leverages the high momentum freestream flow to cause reattachment of the separated flow on the suctionside surface. The reattachment will minimize the wake downstream of the stator vane under off-design conditions and reduce losses. This enables higher vane loading, which can result in lower solidity, i.e., fewer vanes per stage, or even a reduced number of stages to achieve the same pressure rise in the compressor.

\subsection{Motivation and Objectives}

The motivation for this study comes from the desire to develop robust actuators that can function over a range from subsonic to supersonic conditions. The specific objective of this paper is to understand the internal flow structure and the physics of the oscillation mechanisms in such a fluidic diverter actuator by a time-dependent numerical analysis. This understanding will aid in the development of fluidic actuators with minimum pressure losses and advanced designs of flow control actuators. Our previous study, which was limited to subsonic flows (Ref. 19), is extended to include high-speed flows through the internal passages leading to supersonic exit velocities. This study includes cases with supply-to-ambient pressure ratios up to 17.1, corresponding for isentropic air flows to $M a \leq 2.5$, where $M a$ is the Mach number. The coupled velocity, temperature and pressure fields are calculated, and the self-induced oscillatory behavior of the flow is successfully predicted. The results of our numerical studies compared remarkably well to our experimental measurements of oscillation frequencies.

\subsection{Experimental Measurements}

Accompanying experiments are performed to support the numerical modeling effort and to better understand the switching dynamics of the fluidic diverter actuator. A more detailed description of the experimental setup and measurement techniques are given in Reference 20. A simpler schematic is shown in Figure 3. A portion of the fluidic diverter is camouflaged due to the commercially sensitive nature of the information, but the physics of the phenomena and the results of computations discussed below can easily be followed without any sacrifice.

In order to determine the frequency of oscillations of the flow between the two outlets and to monitor the state of the gas flow through the diverter actuator, we use microphones positioned at the approximate center of the device's two outlets. Microphones are more practical for the supersonic flows as compared to the more fragile hot wires used previously for subsonic flows. The reported frequencies are stated with respect to each outlet, i.e. each outlet produces a pulsation of identical frequency, but opposite phase. 


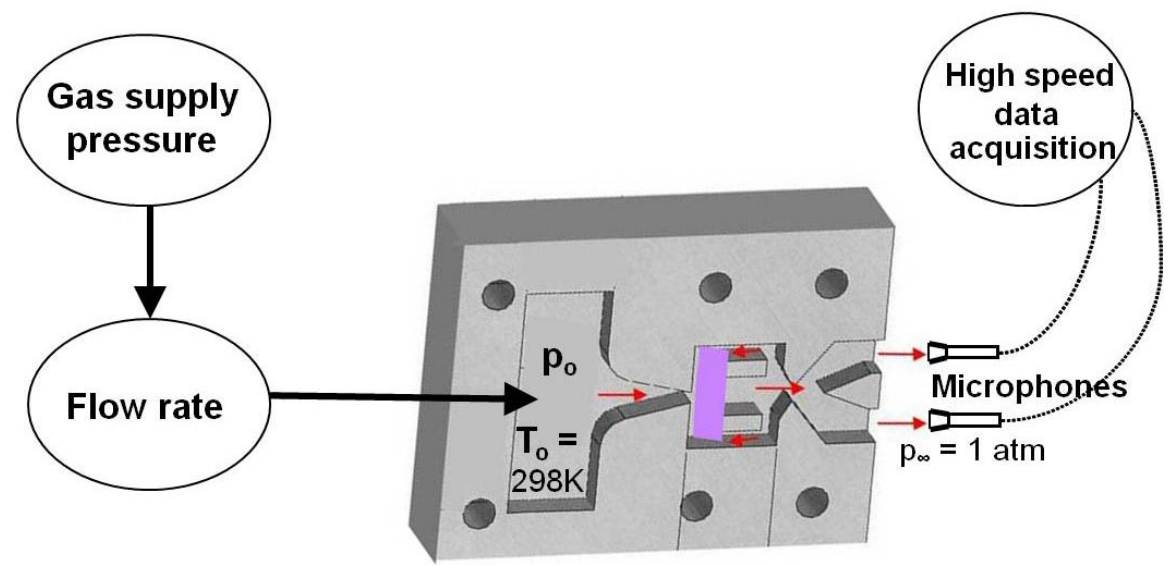

Figure 3.-A simple schematic of the experimental setup.

The flow at each outlet is similar in some respects to a synthetic jet because there is a period of outflow followed by a small amount of inflow. Obviously, the ratio of outflow to inflow is highly skewed since the device requires a pressure source.

The gas supply pressure and its corresponding flow rate and outlet oscillation frequencies are recorded via a high-speed data acquisition system. Oscillation frequencies are found to be insensitive to whether the tests are conducted by keeping the gas supply pressure constant or by performing a blowdown of the initially filled supply. This is expected since the characteristic times of oscillations frequencies are much smaller than the response times of oscillations to the change in source pressure for the blow-down rates we employ; i.e., for the blow-down cases, the oscillation frequencies are practically measured at successively smaller "constant" supply pressures. The measured gas supply pressure is obtained very near to the plenum, within 3 in., and is assumed to have negligible pressure drop before entering the device inlet.

Air is used as the supply gas for most of our experiments, but helium gas is also tried to study the effects of gas thermal properties and sonic speed. The agreement between the numerically predicted and measured oscillations is excellent and described below.

\subsection{Numerical Model}

The numerical investigation uses the standard commercial CFD software FLUENT 6 . The computational domain is two-dimensional (2-D). It uses the beginning of the converging nozzle originating from the supply plenum at constant pressure and $298 \mathrm{~K}$ as the inlet boundary condition and opens to the ambient environment at $1 \mathrm{~atm}$ and $298 \mathrm{~K}$ at the two outlets. The walls are assumed to be at constant ambient temperature of $298 \mathrm{~K}$.

Under isentropic conditions, the ratios of the supply plenum temperature $\left(T_{o}\right)$ and pressure $\left(p_{o}\right)$ at the inlet to the respective flow exit temperature $\left(T_{\infty}\right)$ and pressure $\left(p_{\infty}\right)$ at the outlet are related to the Mach number $(M a)$ as follows:

$$
\begin{gathered}
T_{o} / T_{\infty}=1+(\gamma-1) \cdot M a^{2} \\
p_{o} / p_{\infty}=\left[1+(\gamma-1) / 2 \cdot M a^{2}\right]^{\gamma /(\gamma-1)}
\end{gathered}
$$

where $\gamma$ is the ratio of the specific heat at constant pressure to specific heat at constant volume. A range of supply plenum pressures is analyzed. Assuming that $p_{\infty}$, the ambient pressure, is $1 \mathrm{~atm}$ and the gas medium is air $(\gamma=1.4)$, these supply plenum pressures correspond to Mach numbers from 0.9 to 2.5 . These pressure values and corresponding flow exit temperatures are listed in Table 1. Supply pressures 
higher than the maximum considered here are impractical for application due to the non-linear dependence of pressure on Mach number. This non-linear dependence also makes $M a$ a convenient choice for showing the effect of flow rate and is used throughout the paper for identifying the various cases considered, even though what is actually varied for each case is the corresponding supply plenum pressure. Our computations of the Mach number field inside the diverter show that the $M a=0.9$ case is the smallest supply pressure for which local velocities reach sonic speed levels, defining the beginning of transonic flow in our study.

TABLE 1.-MACH NUMBER VERSUS SUPPLY PLENUM PRESSURE $\left(p_{o}\right)$ AND FLOW EXIT TEMPERATURE $\left(T_{\infty}\right)$ FOR ISENTROPIC FLOW EXPANSION; $p_{\infty}=1$ ATM, $T_{o}=298 \mathrm{~K}$

\begin{tabular}{|c|c|c|}
\hline$M a$ & $\begin{array}{c}p_{o}, \\
\mathrm{~atm}\end{array}$ & $\begin{array}{c}T_{\infty}, \\
\mathrm{K}\end{array}$ \\
\hline 0.9 & 1.69 & 256 \\
1.0 & 1.89 & 248 \\
1.1 & 2.14 & 240 \\
1.2 & 2.42 & 231 \\
1.5 & 3.67 & 205 \\
2.0 & 7.82 & 166 \\
2.5 & 17.1 & 132 \\
\hline
\end{tabular}

For the cases considered in this paper, the Reynolds number is large enough to assume fully turbulent flow and neglect laminar-to-turbulent transition effects. As shown in our previous subsonic study, the $k$ - $\omega$ turbulence model with shear stress transport (SST) offers a more accurate treatment of the near-wall region and is reliable for the type of flows with adverse pressure gradients (as is the situation with the Coanda effect) and shock waves (as is studied here). The effects of full compressibility and viscous dissipation are also properly incorporated into the model for the supersonic cases considered here.

For previous subsonic calculations, a mixture of structured and unstructured quadrilateral mesh elements was used and the sensitivity of the calculations to grid size was checked to ascertain sufficient resolution (Ref. 19). For the supersonic, compressible turbulent flow cases studied here, solution-adaptive grid refinement is employed based on local pressure gradients in order to accurately locate the shocks and resolve the pressure amplitudes. Solution-adaptive grid generation typically ended up with about 134,000 computational cells for all the supersonic cases considered. This number is very close to the number of mesh elements developed and packed carefully into critical areas for the previous subsonic cases, indicating again that sufficient grid resolution is obtained.

For subsonic flows, the pressure-based segregated (uncoupled) algorithm with a constant time step of $1 \times 10^{-5} \mathrm{sec}$ was found to be sufficiently accurate. For supersonic flows, more robust approaches such as pressure-based coupled or density-based algorithms are used with about an order of magnitude smaller time steps to maintain numerical accuracy (Ref. 21). While the pressure-based coupled approach requires more computational memory resources than the pressure-based segregated solver, the tradeoff is in the time to convergence. For high-speed compressible flows, however, the density-based solver is the preferred option because it includes the energy equation in the coupled system, resulting in a single matrix equation to be solved. We also use the second-order upwind scheme, which provides stability for supersonic flows and captures shocks better than the first-order upwind scheme.

At the beginning of the calculations, when the flow is initiated from rest by the supply plenum pressure and starts to make its first pass through the diverter, capturing the flow acceleration and the development of pressure and temperature fields within the diverter accurately is challenging. Furthermore, for supersonic flows, temporal resolution of the transient behavior of successively-generated traveling shock waves requires much smaller time steps than $1 \times 10^{-5} \mathrm{sec}$ (besides the need to use dynamic grid adaption for accurate spatial resolution). Sustaining numerical accuracy during this evolution period is essential for the correct determination of the start-delay time of oscillations. Time steps of the order of $10^{-6} \mathrm{sec}$ are used in our supersonic cases but are varied depending on the Mach number. Time steps are relaxed during the calculations once the flow behavior becomes "pseudo-steady" with regular oscillations 
(with frequencies less than 5,000 Hz). Self-induced oscillatory behavior of the flow is successfully predicted for all the cases studied.

\subsection{Discussion of Results}

As mentioned above, maintaining numerical accuracy is challenging for supersonic flows and time steps smaller than $\sim 10^{-6} \mathrm{sec}$, where it becomes impractical to reach reasonable times for obtaining accurate time-averaged oscillation frequencies. In order to reconcile these conflicting requirements, timestep sizes need to be relaxed in a controlled manner by checking the accuracy of solutions against those obtained from a reliable reference. From considerations of the mathematical formulation of the physical phenomena with coupled mass, momentum and energy conservation equations, the density-based coupled algorithm provides the most accurate numerical description and would be the preferred approach. From the point of view of numerical accuracy, a time step of $\sim 10^{-7} \mathrm{sec}$ is considered a conservative value. Therefore, results generated by the density-based solver with a time step of $1 \times 10^{-7} \mathrm{sec}$ would provide a reference yardstick to compare to those obtained from more efficient algorithms with larger time steps. Furthermore, the initial start-up of the flow through the diverter and its development until the symmetry breaks down to induce the oscillations is the period with the most stringent requirements to preserve numerical accuracy. Hence, we choose the $M a=2.0$ case at $0.20 \mathrm{~ms}$ as the instant to make the comparisons.

Figure 4 shows snapshots at $0.20 \mathrm{~ms}$ for the $M a=2.0$ case obtained from (a) the density-based and (b) the pressure-based coupled solvers for velocity magnitude, absolute pressure, and static temperature fields. The density-based solver uses a time step of $1 \times 10^{-7} \mathrm{sec}$ to serve as the accurate reference case, and the pressure-based solver uses a time step 20 times larger $\left(2 \times 10^{-6} \mathrm{sec}\right)$, so that by $t=0.20 \mathrm{~ms}$ the densitybased solver has already taken 2,000 steps of integration while the pressure-based solver has proceeded only 100 steps of integration. Common scales are used for the results obtained from the two different solvers to make the comparisons more convenient. It is remarkable how the pressure-based coupled solver with a coarser time step was able to generate velocity magnitude, absolute pressure, and static temperature fields so quantitatively similar to the reference case. Therefore, for $M a>1.5$, computations employed the pressure-based coupled solver with time steps not more than $2 \times 10^{6} \mathrm{sec}$. Time step size is relaxed for smaller Mach numbers but not exceeded $1 \times 10^{-5} \mathrm{sec}$.

All snapshots in Figure 4 demonstrate how symmetric the fields are initially. The maximum velocity exceeds $600 \mathrm{~m} / \mathrm{s}$ and multiple shocks are generated both in the central cavity of the diverter and in the exit region where the flow is split towards the two outlets (a1 and b1). More detailed discussions of the initial development of the flow field for different Mach numbers are provided below. The absolute pressure field is relatively uniform at about $2.8 \mathrm{~atm}$ in the central cavity but drops down to sub-atmospheric levels $(\sim 0.2 \mathrm{~atm})$ in the exit region. Assuming that both the gas compression in the central region (from its initial pressure of $1 \mathrm{~atm}$ up to $2.8 \mathrm{~atm}$ ) and the jet expansion in the exit region (from its supply pressure of $7.82 \mathrm{~atm}$ down to $0.2 \mathrm{~atm}$ ) are isentropic processes, Equation (1) and Equation (2) can be combined to predict the expected temperatures:

$$
T_{o} / T_{\infty}=\left(p_{o} / p_{\infty}\right)^{(\gamma-1) / \gamma}
$$

According to Equation (3), the temperature in the central region can warm up to around $400 \mathrm{~K}$ and the jet in the exit region can cool down to around $100 \mathrm{~K}$. These values are quite consistent with the maximum and minimum temperatures shown in Figure 4 (a3 and b3). Indeed, considering that the supply plenum gas temperature (i.e., the total or stagnation point temperature) and the temperature along inner walls of the diverter are taken at $298 \mathrm{~K}$ and that the timescale of the process is less than a millisecond for any appreciable heat exchange, it is reasonable that the operation is close to adiabatic. 


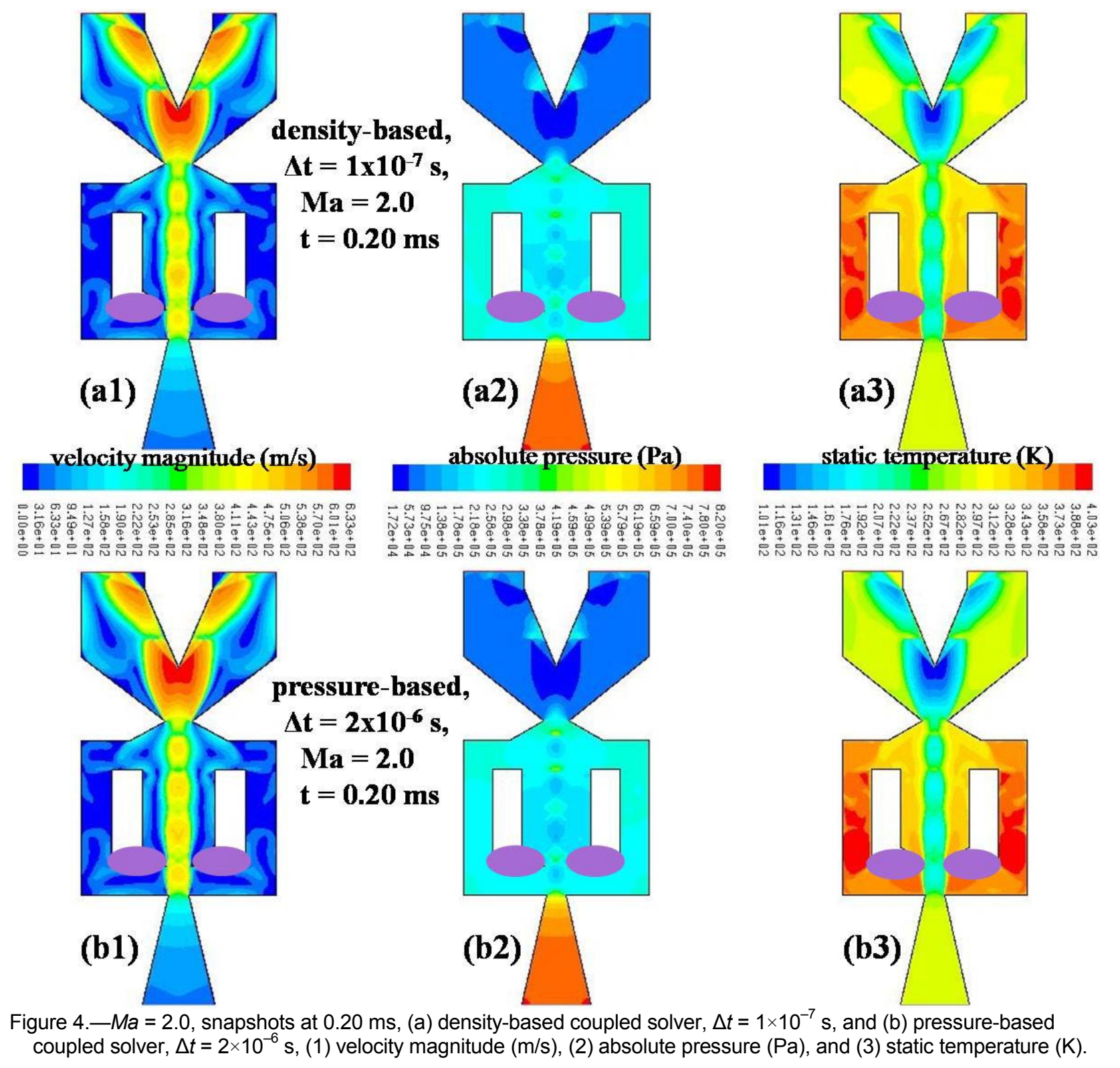

Five sets of time-series calculations for velocity magnitude fields are presented below. The first three sets focus on the initial development of the flow and the onset of oscillations for $M a=1.2,1.5$, and 2.5, and the next two sets depict mature flow oscillations for $M a=1.5$ and 2.5.

The velocity magnitude fields shown in Figure 5 for $M a=1.2$ demonstrate how the flow develops at early times and shock waves start to appear when the flow transitions into the supersonic regime. The flow starts out symmetrically around the central vertical axis. The initial development $(t=0.10$ and $0.25 \mathrm{~ms}$ ) of the flow through the converging nozzle at the bottom, inside the central section, and through the downstream throat before it enters the exit section generates multiple shocks along the stream direction. These are relatively weak shocks which eventually reduce in number and fade away as the flow establishes and the initial disturbances settle down. In about $0.70 \mathrm{~ms}$, the flow symmetry breaks down and the oscillations start. By this time, the initial shocks are dissipated.

When the Mach number increases to 1.5, most of the features mentioned for the $M a=1.2$ case are preserved, as shown by the velocity magnitude time-series plots in Figure 6 . The main difference to note for $M a=1.5$ is that the shock waves are now stronger. They display expanding and contracting widths, 

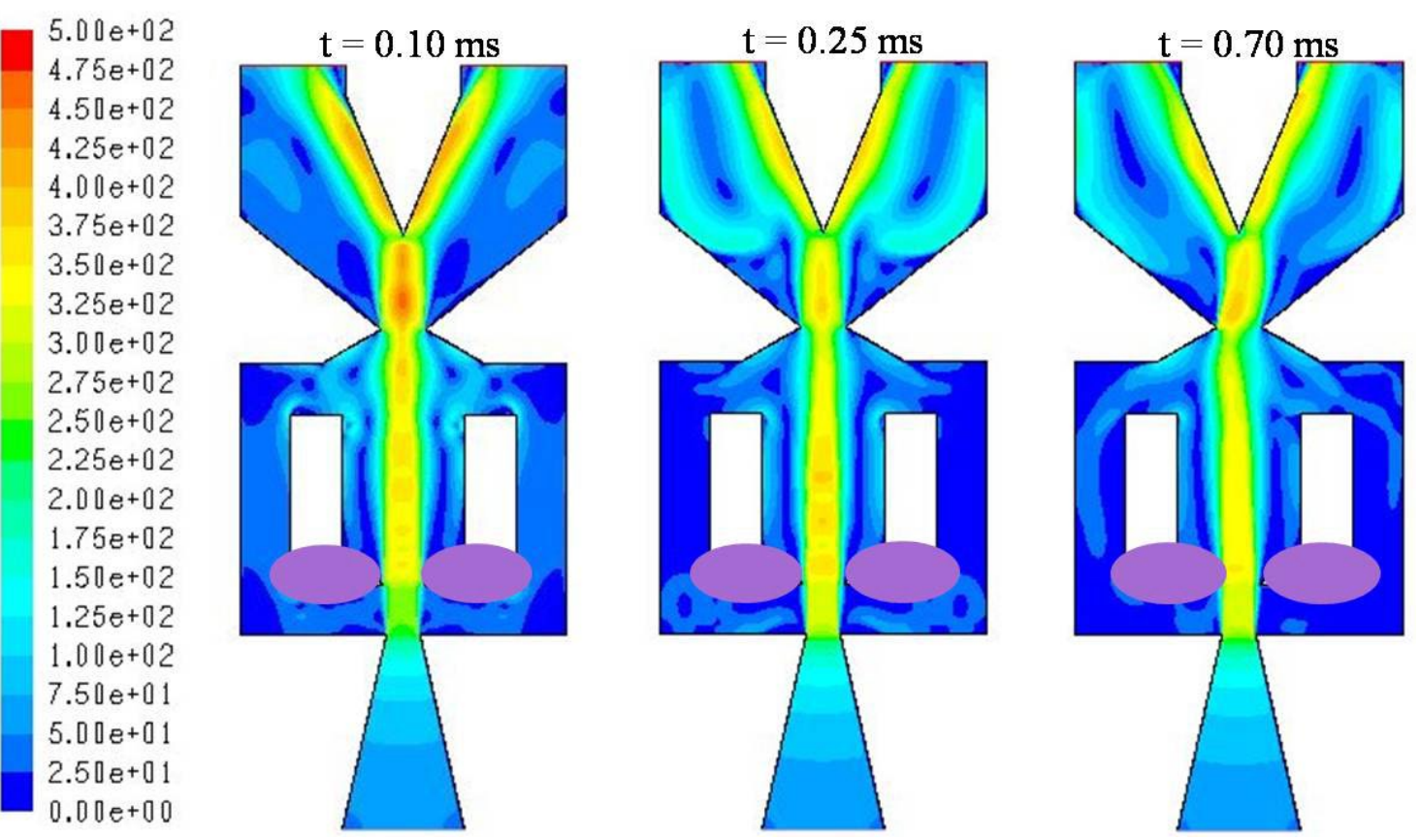

Figure 5.-Ma $=1.2$, velocity magnitude fields $(\mathrm{m} / \mathrm{s})$, snapshots taken at indicated times showing the early appearance of shocks and initiation of oscillations.
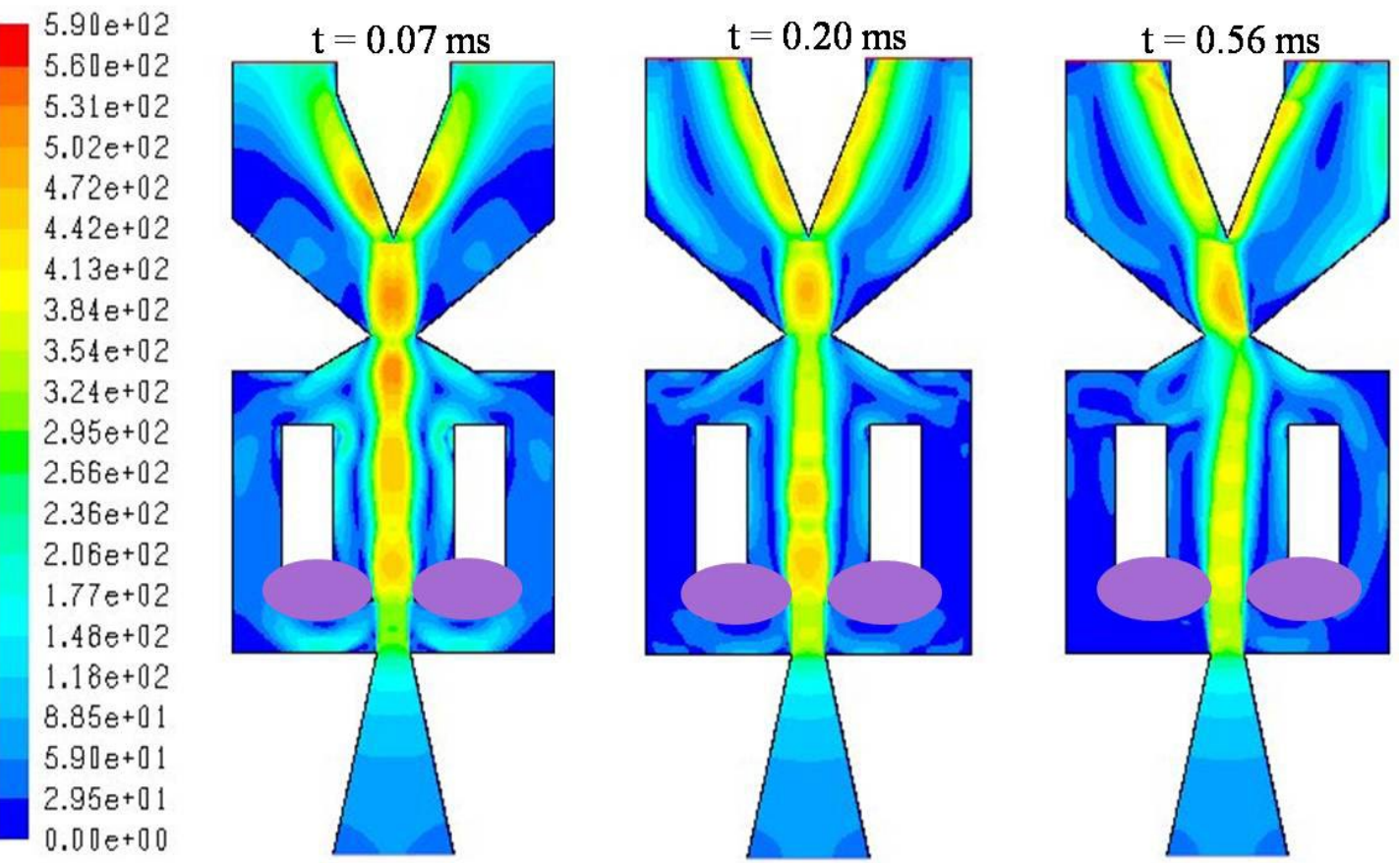

Figure 6.-Ma $=1.5$, velocity magnitude fields $(\mathrm{m} / \mathrm{s})$, snapshots taken at indicated times showing the early appearance of shocks and initiation of oscillations. 
and accelerating and decelerating velocities in a peristaltic motion as they flow downstream $(t=0.07$ and $0.20 \mathrm{~ms})$. They eventually decay in time and space. By the time the left-and-right flow symmetry is broken and the first onset of flow oscillations is observed at $t=0.56 \mathrm{~ms}$, shocks are quite weakened and flow in the central section practically becomes a single jet without much vertical pulsations. Note that the flow accelerates again through the downstream throat into the exit region which subsequently leads to new shocks in the outlets.

The generation of shocks and their development in time and space is most vividly shown in Figure 7 for $M a=2.5$ during the initial stages of the flow through the diverter. They are strong and distinctly resolved. The counteractions of the forward and return flows, combined with their interactions with the shock pressure waves, create interesting recirculation cells in the feedback loops of the central section. As the initial "gush" slows down, the shocks in the central section start to decay as in smaller Mach number cases above. However, in the exit region, planar shocks develop from the splitter tip and reflect from its side surfaces facing the two outlets. Eventually, the flows in the feedback loops dissipate to practical quiescence beyond $0.50 \mathrm{~ms}$ until oscillations develop later on. Throughout this duration, the flow symmetry is maintained along the vertical axis in all sections of the diverter.

It should be mentioned that cases around the transonic region have been the most challenging from the computational point of view. The convergence of cases for Mach numbers in the range of 0.9 to near 1.5 have required special care in numerical parameters. Their convergence rates have been slower than typical subsonic or supersonic cases for $M a>1.5$. This computational difficulty is mainly due to the development of transonic flow in the central section of the diverter when the bottom nozzle is mostly choked but the top nozzle downstream has not fully choked yet, as will be further discussed below.

It has been indicated that both fluid inertia and acoustic waves affect the speed of the feedback signal (Ref. 22). We have shown in our previous work on subsonic flows that the time for the first onset of instability leading to oscillations, called the start delay time, is shorter for faster flows and levels off as the sonic velocity is approached (Ref. 19). This trend is demonstrated for different gases like air and helium and for different operating temperatures of the same gas, also suggesting that the phenomenon is related to acoustic speed. In this work, when the operation of the diverter is extended to supersonic
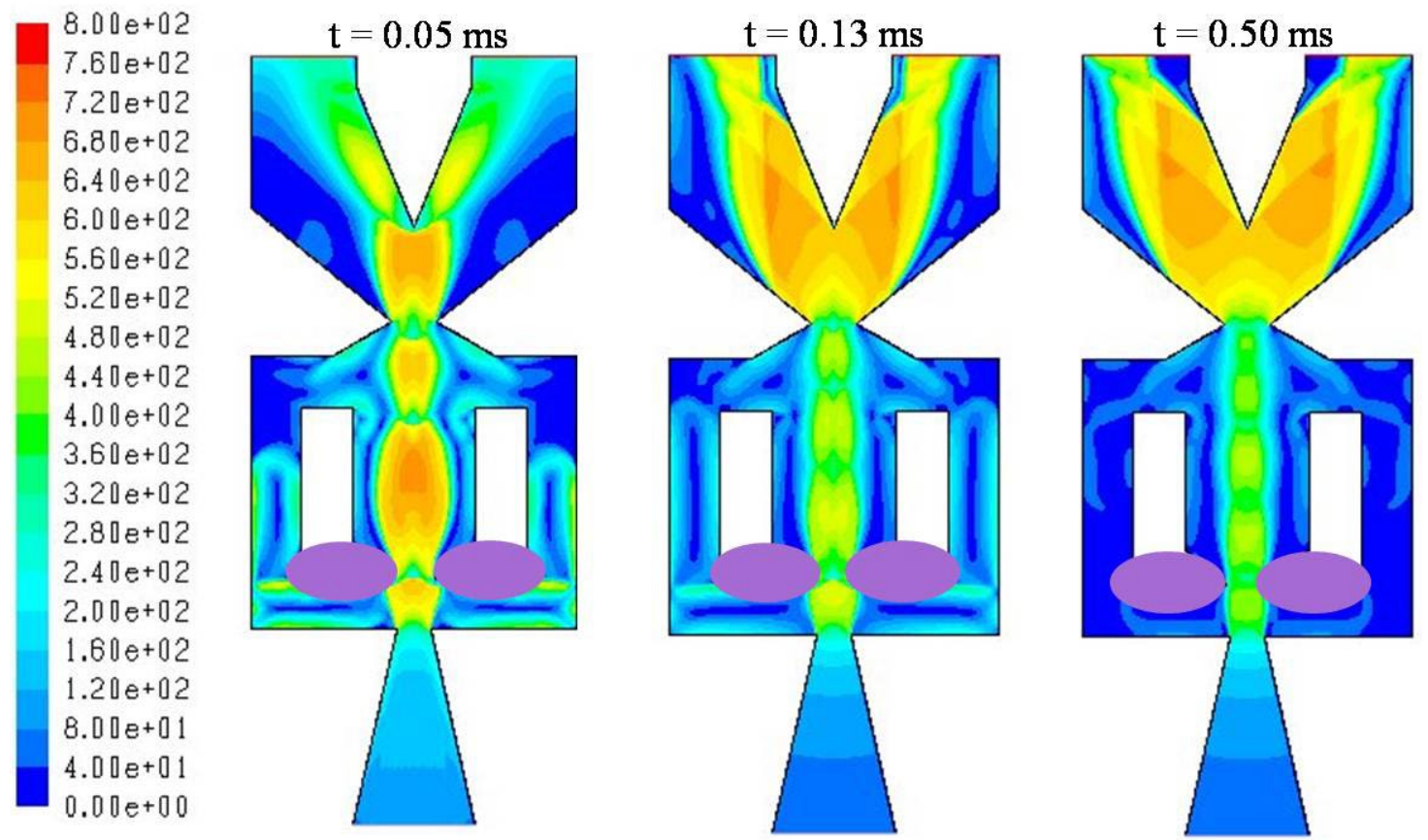

Figure 7.-Ma $=2.5$, velocity magnitude fields $(\mathrm{m} / \mathrm{s})$, snapshots taken at indicated times showing the early appearance of shocks and initiation of oscillations. 
conditions, it is seen in Figure 8 that the oscillation start delay time indeed reaches a minimum at a supply plenum temperature of $298 \mathrm{~K}$ for air (red solid curve). Since the acoustic speed depends directly on the square root of $\gamma$ and temperature and inversely on the square root of molecular weight, the acoustic speed is increased either by switching from air to smaller molecular weight helium gas $(\gamma=1.67)$ at $298 \mathrm{~K}$ or by increasing the operating temperature from 298 to $1200 \mathrm{~K}$ for air. In practice, the use of helium or such a high operating temperature may not be realistic but employed here as an artificial numerical experiment. The curves for larger acoustic speeds (pink and green) show a similar curvature to the one for air at $298 \mathrm{~K}$ (red) and start to level off as the flow starts to choke $(M a \approx 1)$ at the end of the bottom converging nozzle.

When the start delay time is plotted against an equivalent Mach number, for which the actual Mach number is normalized with respect to air properties at $298 \mathrm{~K}$ by accounting for the effects of $\gamma$, temperature, and the molecular weight of the medium, then all points collapse to a single curve as shown in Figure 9. Some of the subsonic Mach numbers for the case of helium gas at $298 \mathrm{~K}$ and for the case of air at $1200 \mathrm{~K}$, as shown in Figure 8, become supersonic when converted to their equivalent Mach numbers as shown in Figure 9.

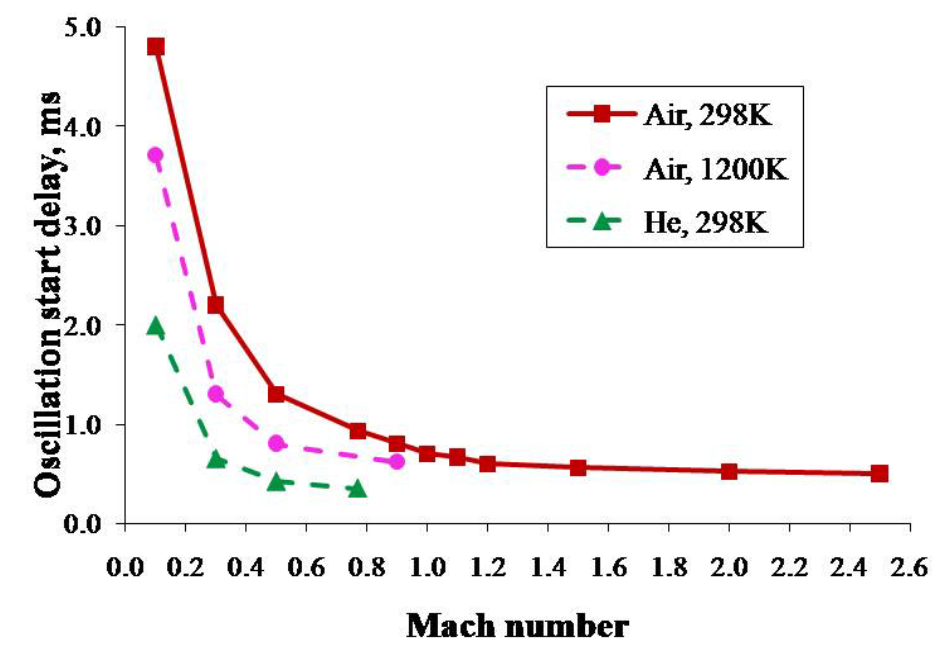

Figure 8.-Initial delay time for oscillations to start (ms) versus Mach number.

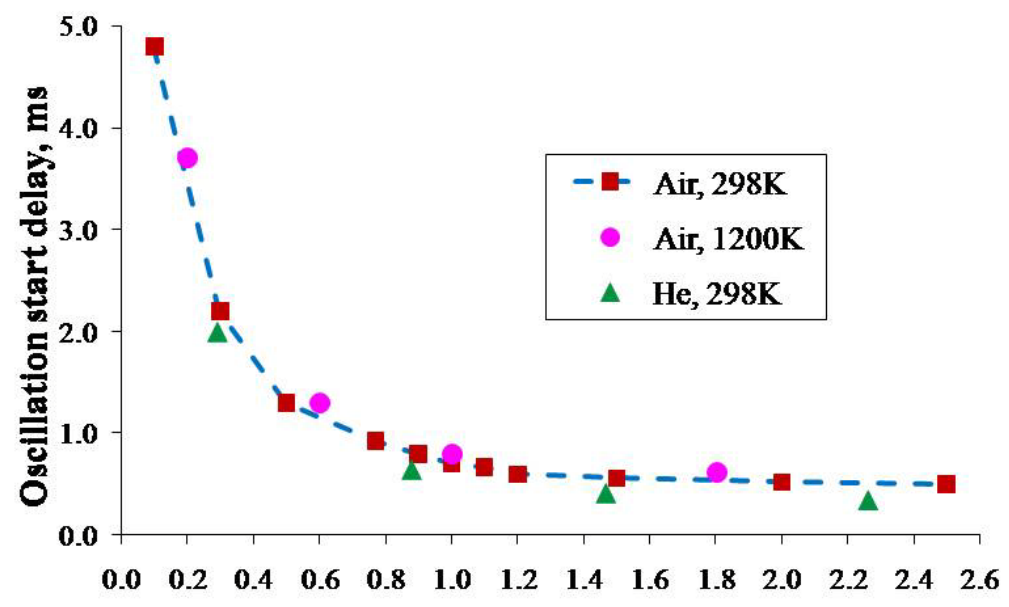

Air-298K-equivalent Mach number

Figure 9.-Calculated initial delay time for oscillations to start (ms) versus Mach number equivalent to that of air at $298 \mathrm{~K}$. 
It should be noted that this single curve for oscillation start delay time with respect to the equivalent Mach number in Figure 9, covering a range from subsonic to supersonic flows up to $M a=2.5$, indicates that the initiation of the oscillations is not due to some build-up of numerical inaccuracy during the time integration in computations. Such accumulation of numerical error would result in a more random breakup of flow symmetry depending on the Mach number as well as the computational parameters. In fact, the symmetry-breaking forces in the lateral direction are induced by actual physical phenomena created by the shear-induced vortices shed from the jet when the flow leaves the lower nozzle and enters the central cavity. These disturbances generate acoustic waves and fluid inertia through the feedback loops, which eventually become large enough to bend the flow toward one outlet channel. Once the symmetry is broken, the feedback loops reverse the direction of the lateral push in the nozzle region, flipping the axial flow to the opposite side and hence starting the periodic oscillations. The oscillatory behavior is discussed in more detail below.

The next two time-series graphs of velocity magnitude show the established oscillations for the two supersonic cases of $M a=1.5$ and 2.5 at about $10 \mathrm{~ms}$ after the initiation of the flow. Figure 10 depicts six snapshots taken at $0.08 \mathrm{~ms}$ intervals for $M a=1.5$. The pink arrows in the exit region show the instantaneous direction of the sweeping motion of oscillations at those particular times, including the situation when the flow is just about to reverse direction as in $10.03 \mathrm{~ms}$. The first observation is that, relative to Figure 6 , shocks inside the central cavity have disappeared by this time. The flow is choked at the bottom converging nozzle and becomes supersonic in the lower section of the cavity due to the geometric expansion in this region. The flow then slows down towards the downstream throat area where the oscillations occur by the influence of lateral flows from the feedback loops. By the time the Mach number reaches 1.5, the flow is sufficiently large to choke also at the top throat. The expansion after the top throat allows the flow to go supersonic again in the exit region. Shock waves, albeit not so strong, can be observed as the flow continues to oscillate in the outlets. The symmetry and sinusoidal periodicity of oscillations are not much different than its previously studied subsonic counterparts. Again similar to subsonic flows, flow directions at the exit planes, as well as inside the outlet channels, clearly demonstrate the suction from outside, recirculation cells, and stagnation zones over a period spanning a full cycle. The snapshots taken at $9.95 \mathrm{~ms}$ (first frame) and $10.35 \mathrm{~ms}$ (last frame) look remarkably similar, indicating that the oscillation period is about $0.40 \mathrm{~ms}$; i.e., oscillation frequency of about $2500 \mathrm{~s}^{-1}$.

Note that there is a range of flow rates for which the bottom nozzle is choking while the top throat has not choked yet. It is this "transitional range" during which the flow inside the central cavity is transonic and quite unsteady, rendering the computations more challenging for convergence. Besides the lateral sweeps, there are also flow oscillations in the axial direction (see the moving iso-velocity-magnitude color lines at subsequent snapshots in figures). The developing boundary layer around the converging nozzle builds sufficient thickness at the nozzle throat location to allow the passage of downstream flow information upstream of the throat, thereby generating axial oscillations. The animations of timedependent calculations clearly demonstrate, especially during the transitional range of flow rates $(\sim 0.9<$ $M a<\sim 1.5$ ), that the bottom nozzle throat does not choke steadily and that there are axial (choke-relief) pulsations during this flow range. Such "leakage" of pressure information upstream due to incomplete choking and the resulting axial oscillations lead to unsteady, but periodic, attachment and detachment of flow at the two tips of the nozzle. As the flow rate is further increased to $M a>1.5$, both bottom and top nozzles choke more completely and the axial oscillations start to dampen, as shown below.

When the Mach number is increased to 2.5, as shown in Figure 11, the first observation again is that, relative to Figure 7, shocks inside the cavity have completely disappeared as mature oscillations are established. The choked flow through the converging nozzle gets issued into and crosses the central cavity as a jet. The downstream throat is also choked. When the jet expands from the top throat into the exit section, strong shocks are generated by the supersonic expansion. Planar shock waves, split by the tip of the divider, exist in both outlets at all times during the oscillations and reflect from the inner side-surfaces of both the diverter and the outlets. 


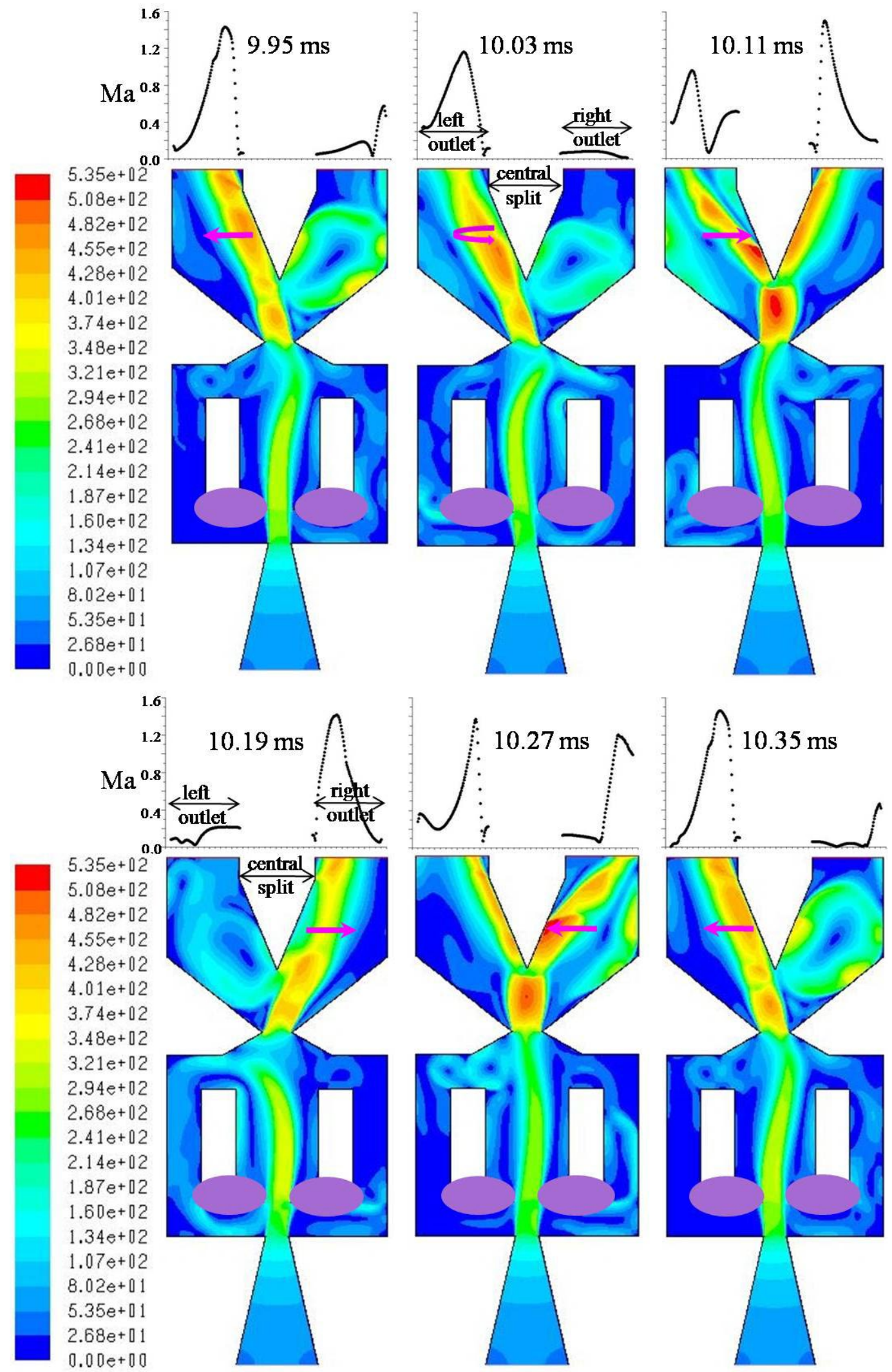

Figure 10. $-M a=1.5$, velocity magnitude fields $(\mathrm{m} / \mathrm{s})$, snapshots taken at indicated times showing regular oscillations. 

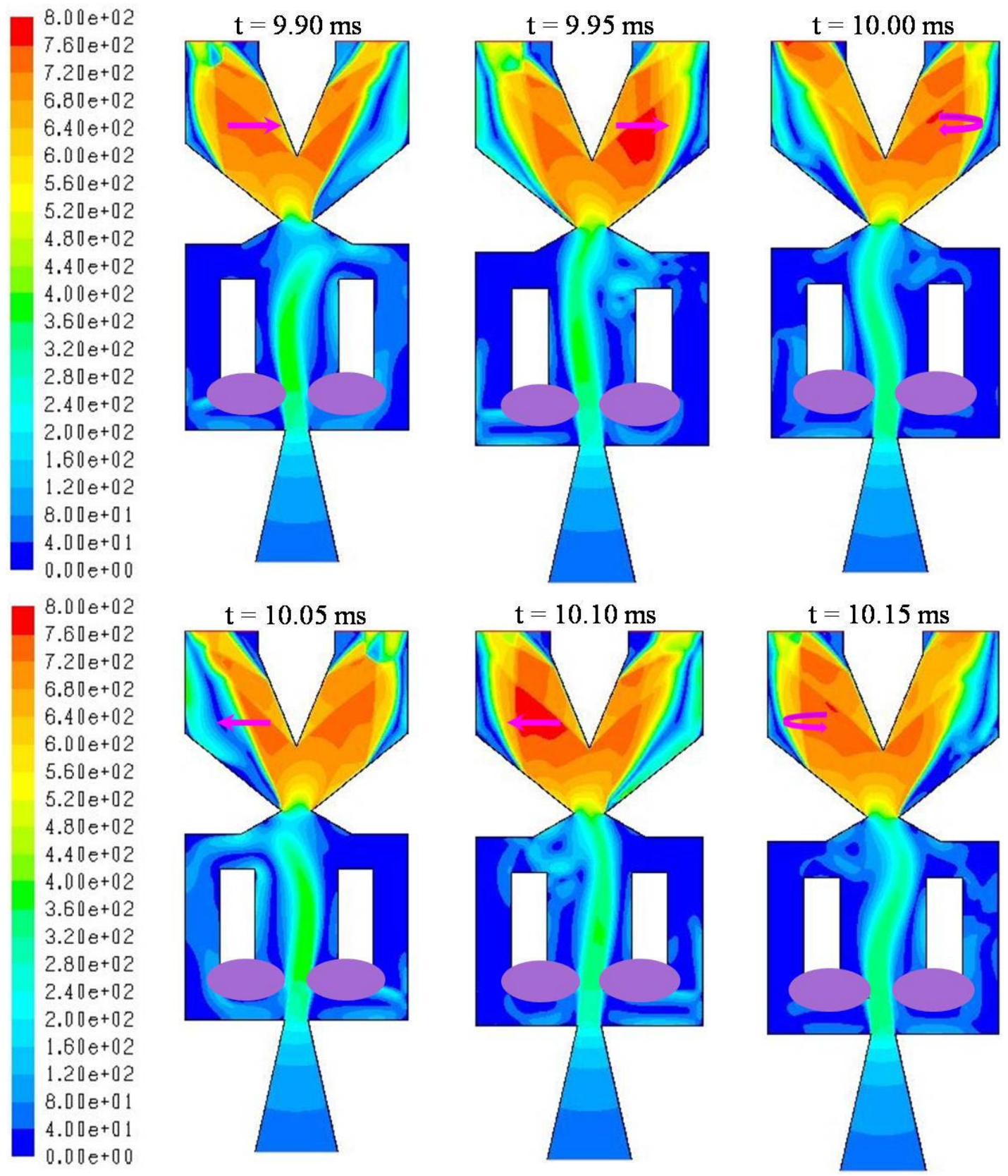

Figure 11. $-M a=2.5$, velocity magnitude fields $(\mathrm{m} / \mathrm{s})$, snapshots taken at indicated times showing regular oscillations. 
Comparison of snapshots taken at $9.90 \mathrm{~ms}$ (top row first fame) and $10.05 \mathrm{~ms}$ (bottom row first frame) indicates that the half-period of oscillations is about $0.15 \mathrm{~ms}$; i.e., oscillation frequency is a little over $3000 \mathrm{~s}^{-1}$. The time-averaged oscillation frequencies given in Figure 14 are obtained from animations generated from computations.

Note that for this highest Mach number case, there is always flow in the outward direction occupying both outlet channels at all times during the oscillations. The flow does not completely switch from one side to the other; instead, its intensity shifts periodically between the two channels. Again, the pink arrows show the instantaneous direction of oscillatory motion, including times very close to reversal of direction as at $10.00 \mathrm{~ms}$ and $10.15 \mathrm{~ms}$. Figure 12 provides a magnified and clearer picture of the outlet region by showing the velocity vectors in a time series of snapshots. Flow suction from outside and recirculation cells inside the channels, observed at lower Mach numbers, are minimized, if not completely eliminated. Although the amount of flow in each outlet channel varies in time (i.e., volumetric flowrate) the maximum velocities on either side remain comparable at all times.

Distinct "flip-flop" actions between the two outlets start to decay as the Mach number gets larger. For this particular diverter, this shift is observed at around $M a=2.0$. Figure 13 revisits the case for $M a=2.0$ (shown in Figure 4) sometime after the steady oscillations fully develop, specifically at $4.75 \mathrm{~ms}$ when the oscillation direction starts to switch before the flow completely sweeps the outlet on the right-hand side or clears the outlet on the left-hand side. This case represents a transition from distinct flip-flops, as the case for $M a=1.5$ or smaller, to occupation of both outlets during oscillations (or "spill over" into the other channel), as the case for $M a=2.5$. Strong and multiple shocks are always present in the exit region.
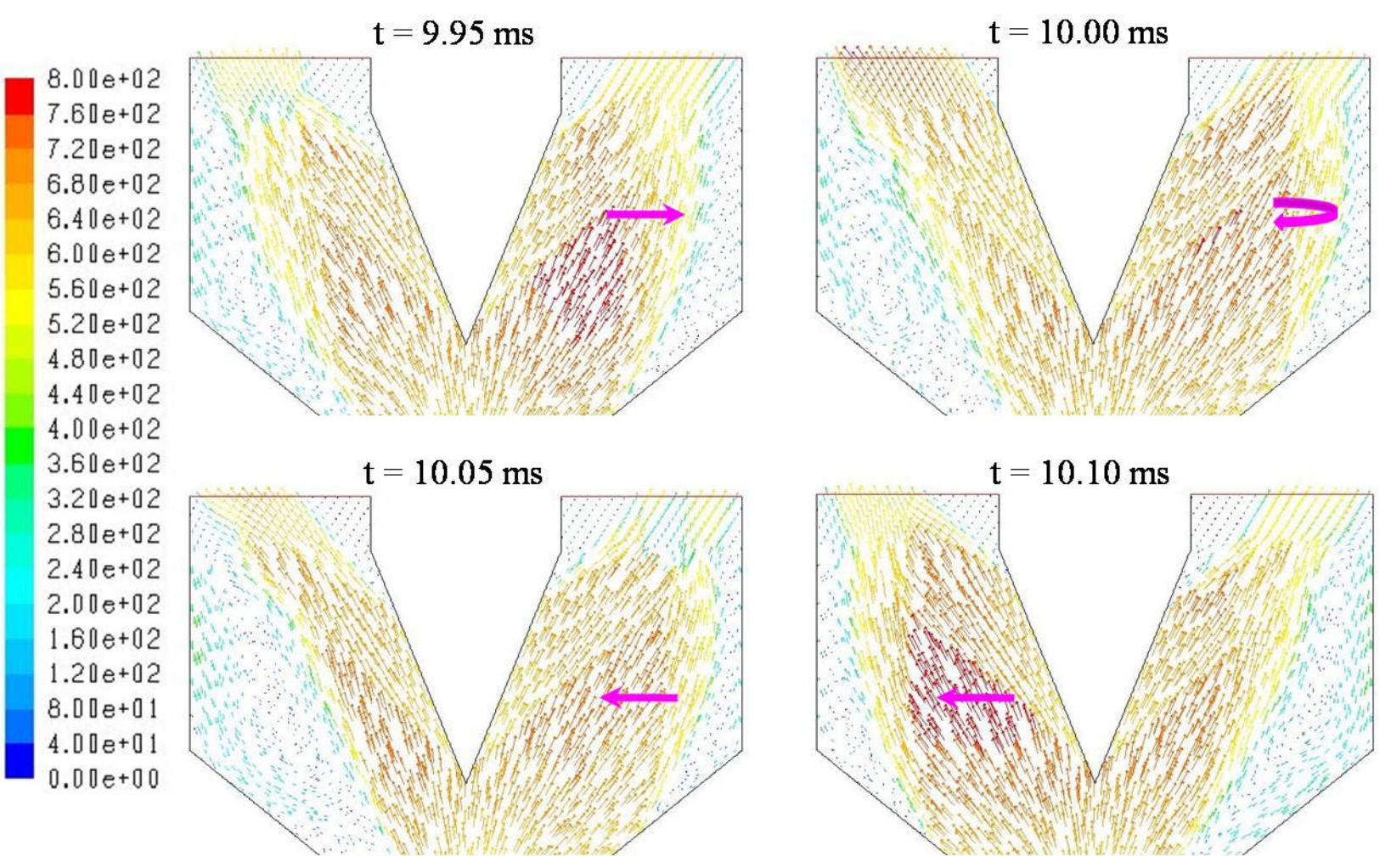

Figure 12. $-M a=2.5$, velocity vectors $(\mathrm{m} / \mathrm{s})$, snapshots taken at indicated times $(\mathrm{ms})$ showing flow direction at exit planes, recirculation rolls, and stagnation zones in outlet channels. 

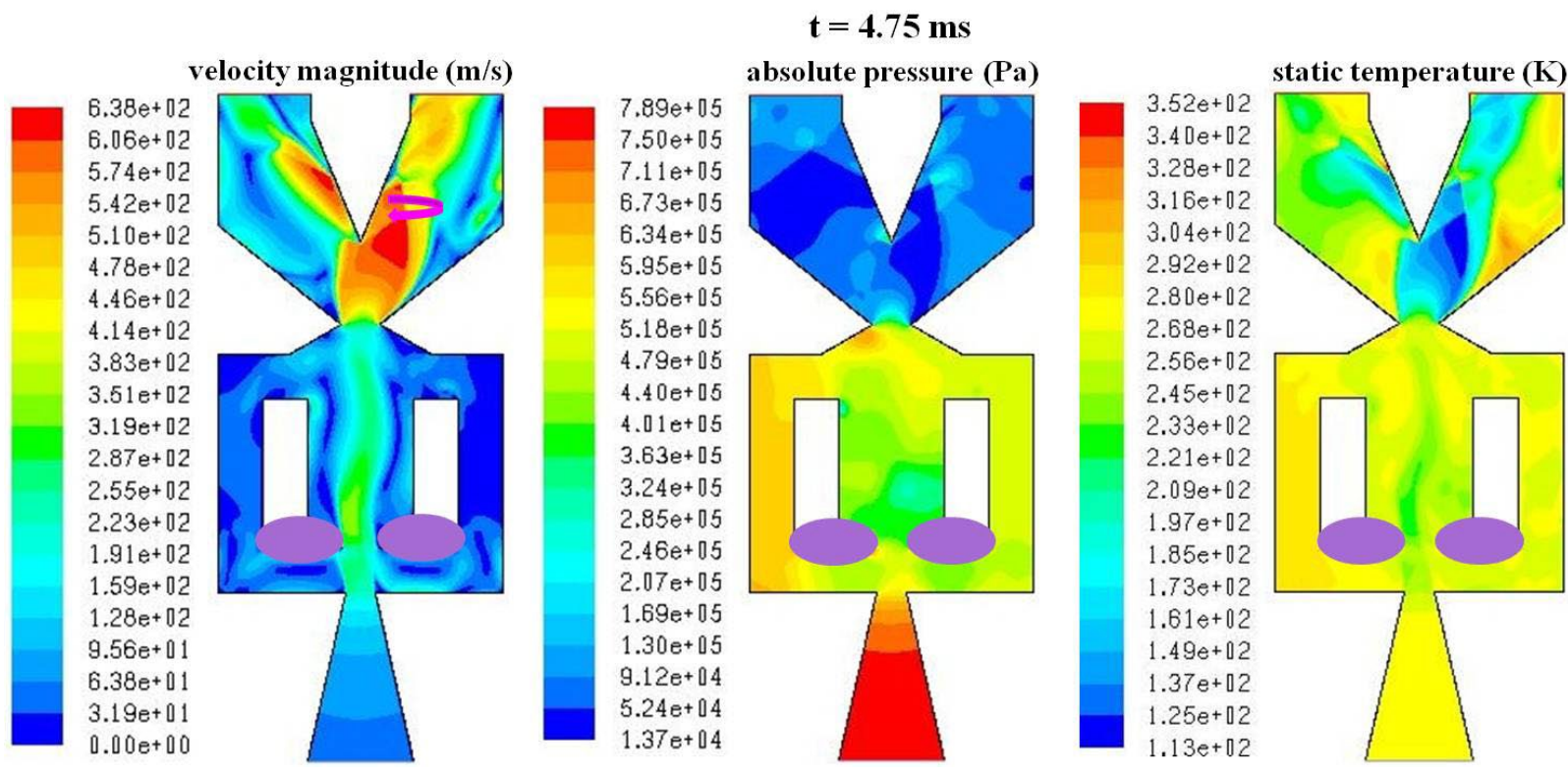

Figure 13. $-M a=2.0$, velocity magnitude $(\mathrm{m} / \mathrm{s})$, absolute pressure $(\mathrm{Pa})$, and static temperature $(\mathrm{K})$ fields at $4.75 \mathrm{~ms}$.

Figure 13 also demonstrates that the maximum velocity, minimum absolute pressure, and minimum static temperature values after the establishment of mature oscillations are similar to those observed in Figure 4 before the start of oscillations. This is expected since the flow physics and thermodynamics, as discussed above for Figure 4, is maintained close to isentropic conditions in this brief time frame. One noticeable difference is the cooler and more uniformly distributed static temperature in the central section. This is due to the convective mixing of cooler jet flow in the central cavity with the originally compressed, warmer gas in the feedback channels. The mixing generated by the oscillatory fluid motion in the feedback loops is clearly shown by the velocity magnitude field in Figure 13. In the exit region, the temperature field is affected by the outside gas at $298 \mathrm{~K}$ entrained into this area and partially mixing with the cooler outgoing flow. The interaction of the incoming outside flow with the outgoing jet in the exit region also induces some shear friction, generating heat by viscous dissipation, as reflected in locally increased levels of temperature. Note that the absolute pressure in the exit region drops below the outside ambient condition to sub-atmospheric levels due to the expansion of the supersonic flow. The corresponding lower temperatures observed in the same region are consistent with isentropic processes as they can be described quantitatively by Equation (3) given above. For example, using the maximum and minimum absolute pressures of $7.89 \times 10^{5}$ and $1.37 \times 10^{4} \mathrm{~Pa}$ and maximum temperature of $352 \mathrm{~K}$ in Figure 13, we can estimate the minimum expected temperature from Equation (3) as $111 \mathrm{~K}$, which is consistent with the computed value of $113 \mathrm{~K}$ reported in Figure 13. Even when the outside ambient pressure is lower than atmospheric, the same phenomenon that the absolute pressure in the outlets would fall below the ambient level would be expected as the physics of the isentropic flow process inside the fluidic diverter is governed mainly by the ratio of the supply pressure to the outside pressure.

The transition from the complete-switching mode, where the flow occupies only one outlet before switching direction, to the "spill-over" mode, where the flow shifts only partially between the outlet channels, would depend on the internal geometrical details and dimensions such as the length of the feedback channels. Since the top throat also starts to get choked when $M a>1.5$ for this diverter, the acoustic effect in the feedback loops is minimized at higher Mach numbers. Therefore, for $M a>\sim 2$, this diverter can be further optimized for operation by considering only geometric factors. Reducing the thickness of the splitter would be a possibility. Complete elimination of the splitter, allowing only a sweeping oscillatory motion of a single jet, may also be considered. 


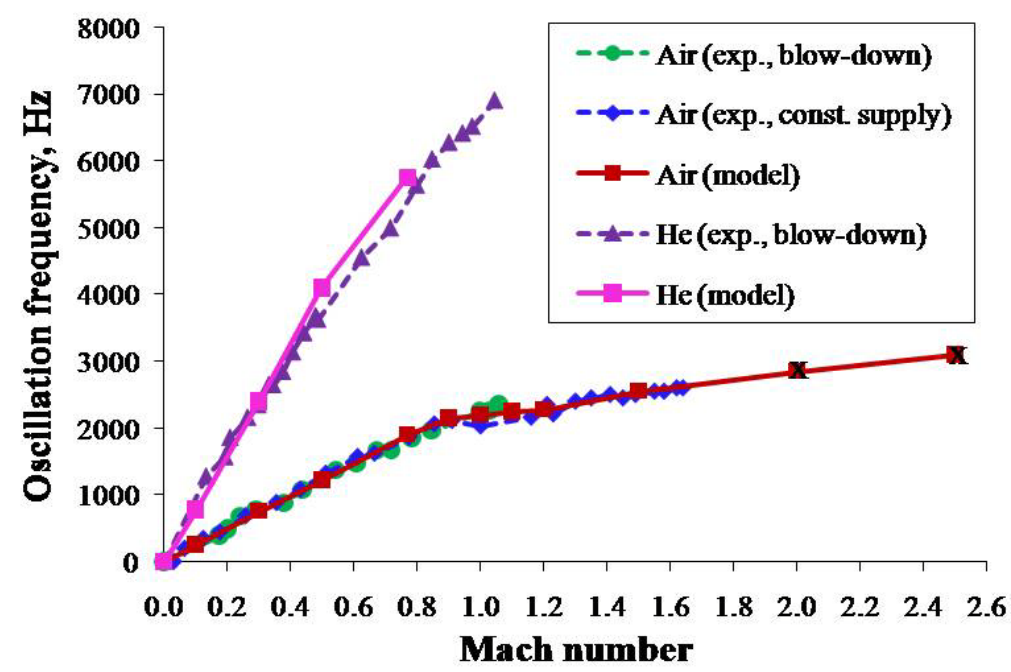

Figure 14.-Comparison of calculated and measured oscillation frequencies of the fluidic diverter versus Mach number.

One important observation, however, is that this diverter is capable of producing supersonic exit velocities. The outlet exit velocities exhibit axial pulses besides the lateral oscillatory sweeping motion across the exit plane. Furthermore, flow exit temperatures are cooler than that of the ambient for supersonic operation of the diverter so that the gas density of the exiting flow is larger than that of the ambient. Such features are significant to enhance penetration into the freestream and promote better mixing for effective flow control.

The frequencies of oscillations generated by the fluidic diverter are measured experimentally by using room temperature air or helium gas as described briefly in Section 4.0. The stated frequency is with respect to each outlet. Figure 14 shows that the measured and numerically calculated frequencies as a function of Mach number. The Mach number is calculated from Equation (2) by using either the measured air or helium supply pressure or the plenum pressure applied as a numerical inlet boundary condition. The agreements between the experimentally measured and numerically calculated oscillation frequencies are excellent for both air and helium and the full of range of Mach numbers, up to the maximum measured value of 1.7 for air. Oscillation frequencies for helium at a given Mach number are larger than those for air due mostly to the higher sonic speed. The larger frequencies for helium makes the computations more challenging since the time step size needs to be accordingly reduced for accurate resolution. Therefore, the supersonic computations for helium are not deemed practical. As discussed in Section 4.0, measured oscillation frequencies do not depend on whether the tests are conducted by keeping the gas supply pressure constant (blue diamonds) or by performing a blow-down of the initially filled supply (green circles).

The slope of the curve for air changes around Mach number of unity. This change is also predicted by the computations when the bottom converging nozzle starts to choke. When the flow is around the transonic region with Mach number between about 0.9 and 1.3, the experimental measurements of oscillation frequencies for air (blue diamonds) also demonstrate an unsteady behavior, just as the convergence of computations become harder as discussed above. The physical interactions in the central section of the diverter for this range of flow rates render the oscillations quite sensitive to flow behavior inside the cavity and in the feedback loops. In fact, if the diverter behavior at higher flow rates had not been explored, one would have concluded a saturated performance at supersonic speeds due to choking. However, the curve seems to recover from its plateau with an inflection point at $M a=\sim 1.3$ and the oscillation frequency still continues to grow with respect to Mach number at higher flow rates, albeit at a slower rate relative to subsonic flows. 
The two computational red square points for air at $M a=2.0$ and 2.5 are marked also with " $\mathrm{x}$ " to indicate that although the oscillations seem to continue and their frequencies can still be counted, the diverter outlets do not have complete and clear switching from one side to the other, i.e., the "spill-over" mode as discussed above. Despite the fact that the curve seems to extend with the same constant slope, this behavior would presumably lead to a decay of oscillations at even higher Mach numbers due to the complete choking of the top nozzle downstream.

The depth of the diverter in its third dimension is comparable to its width. The wall effects, viscosity, and turbulence are clearly important to this problem, and the accurate prediction of pressure losses and velocities would require a 3-D analysis. However, the pressure waves and fluid momentum responsible for creating the perturbations for the oscillatory flow are transferred around the feedback channels and through the central cavity; i.e., mainly in a $2-\mathrm{D}$ path, as discussed above. Therefore, for our purpose of predicting oscillation frequencies, the key physics can be captured mainly by a $2-\mathrm{D}$ analysis. Indeed, our success in being able to predict the oscillation frequencies compared to experimental measurements for two different gases with substantially different properties attests to the validity of the 2-D approach.

\section{Conclusions}

Current state-of-the-art actuation methods have problems with reliability and effectiveness, especially in the turbine environment, and are not practical at the system level due to considerations such as volume, weight, power and cost. The goal is to develop viable, unsteady fluidic actuators with high control authority and also improve their performance efficiency by minimizing pressure losses for flow control applications in propulsion systems and on airframes operating in a wide range of flow speeds.

Towards this end, a time-dependent computational analysis of a specific fluidic diverter is conducted with an objective to gain understanding of its internal flow details. The velocity, temperature, and pressure fields are calculated, and our previous subsonic computations are extended to supersonic speeds up to $M a=2.5$. Self-induced flow oscillations inside of the diverter are successfully predicted for the explored range of Mach numbers. The predicted oscillation frequencies have excellent agreement with our experimental measurements of the device for both air and helium operating gases. It is determined numerically that this diverter is capable of producing supersonic exit velocities.

The frequency of self-induced oscillations increases linearly with the flow rate (Mach number) through the fluidic diverter; however, the slope of the dependence is different for subsonic and supersonic flows and for different gases. Although the frequency seems to saturate for transonic flow speeds, the internal geometry of the diverter allows for increasing frequencies at higher, supersonic Mach numbers.

The outlet exit velocities exhibit pulses in the axial direction besides the lateral oscillatory sweeping motion across the exit plane. Furthermore, temperatures of the flow exiting the diverter are cooler than that of the ambient for supersonic operation so that the gas density of the exiting flow is larger than that at the outside. Such features are significant to enhance penetration into the freestream and promote better mixing for effective flow control.

The delay time for the instability of the initially symmetric flow to develop and for the steady, periodic oscillations between the two outlets to start is shown to decrease with flow rate and levels off at a minimum when the Mach number exceeds unity.

Dimensions of the specific fluidic diverter studied in this paper, such as the length of the feedback channels, are fixed, thereby limiting the parameter space of exploring the physical mechanisms of selfinduced oscillations such as momentum and acoustic feedback. The observed evidence obtained by varying the flowing gas (air versus helium) and the operating temperature ( $298 \mathrm{~K}$ versus $1200 \mathrm{~K}$ ) for the range of Mach numbers used in this study indicates that the acoustic speed in the gaseous medium is a key factor in governing the mechanism of initiating the oscillations up to sonic speeds, as well as determining their frequency for all Mach numbers. While the effect of sonic speed on initiating oscillations diminishes for supersonic conditions, the frequency of oscillations continues to grow, though at a slower pace, in the supersonic region. 
The computed flow, pressure, and temperature fields inside the diverter are consistent with isentropic compression and expansion processes, allowing their estimations from simple equations.

Another important finding is the fact that this fluidic diverter transitions from a "flip-flop" mode to a "spill-over" mode at $M a \sim 2.0$. Although oscillation frequencies continue to increase linearly up to $M a=$ 2.5 , this observation points to a potential decay in diverter performance at further higher speeds. Our computations indicate that geometric design improvements of the actuator are possible in order to prevent such a spill-over at higher supersonic speeds.

We plan to investigate the operation of an array of diverters in an attempt to synchronize the outputs of the device, as well as use the current numerical model for design optimization of the fluidic diverter and similar unsteady fluidic actuators.

\section{References}

1. Gad-el-Hak, M., Flow Control: Passive, Active, and Reactive Flow Management, Cambridge, NY, Cambridge University Press 2000. ISBN 05217700689780521770064.

2. Culley, D.E., Bright, M.M., Prahst, P.S., Strazisar, A.J., "Active Flow Separation Control of a Stator Vane Using Embedded Injection in a Multistage Compressor Experiment," Journal of Turbomachinery, Vol. 126, No. 1, January 2004, pp. 24-34.

3. Kirtley, K.L., Graziozi, P., Wood, P., Beacher, B., Shin, H-W., "Design and Test of an Ultra-Low Solidity Flow-Controlled Compressor Stator," GT2004-53012, Proceedings of the International Gas Turbine Institute, June 2004.

4. Cattafesta III, L.N., Garg, S., Choudhari, M. and Li, F. "Active Control of Flow-Induced Cavity Resonance," AIAA Paper 97-1804, 28th Fluid Dynamics Conference, Snowmass Village, CO, June 29-July 2, 1997.

5. Amitay, M., Kibens, V., Parekh, D.E., and Glezer, A., "Flow reattachment dynamics over a thick airfoil controlled by synthetic jet actuators," AIAA Paper 99-1001.

6. Raman, G. and Kibens, V., "Active flow control using integrated powered resonance tube actuators," AIAA-2001-3024, 31 ${ }^{\text {st }}$ AIAA Fluid Dynamics Conference and Exhibit, Anaheim, CA, June 11-14, 2001.

7. Kastner, J and Samimy, M., "Development and characterization of Hartmann tube fluidic actuators for high-speed flow control," AIAA Journal, Vol. 40, No. 10, pp. 1926-1934, 2002.

8. Dziuba, M. and Rossmann, T., "Active control of a sonic transverse jet in a supersonic cross flow using a powered resonance tube", AIAA-2005-897, 43 ${ }^{\text {rd }}$ AIAA Aerospace Sciences Meeting and Exhibit, Reno, NV, Jan. 10-13, 2005.

9. Zhuang, N., Alvi, F. S., Alkislar, B., and Shih, C., "Supersonic Cavity Flows and Their Control," AIAA Journal, Vol. 44, No. 9, 2006, pp. 2118-2128.

10. Ali, M.Y., Solomon, J.T., Gustavsson, J., Kumar, R., and Alvi, F.S., "Control of Resonant Flow Inside a Supersonic Cavity Using High Bandwidth Pulsed Micro-actuators," AIAA-2010-1198, 48 AIAA ASM Conf., Orlando, FL, Jan. 4-7, 2010.

11. Raghu, S., "Feedback-free Fluidic Oscillator and Method," U.S. Patent 6,253,782, issued July 3 , 2001.

12. Gregory, J.W., Sullivan, J.P., Raman, G and Raghu, S. "Characterization of a micro fluidic oscillator for flow control," 2004 AIAA-2004-2692.

13. Guyot, D., Taticchi Mandolini Borgia, P., Paschereit, C. O., and Raghu, S., "Active Control of Combustion Instability Using a Fluidic Actuator," AIAA-2008-1058, $46^{\text {th }}$ AIAA Aerospace Sciences Meeting and Exhibit, January 7-10, 2008, Reno, NV.

14. Raman, G., Hailye, M., and Rice, E. J., "Flip-flop jet nozzle extended to supersonic flows," AIAA Journal, Vol. 31, No. 6, 1993, pp. 1028-1035.

15. Michael DeSalvo, M., Edward Whalen, E., and Ari Glezer, A, "High-Lift Enhancement using Fluidic Actuation," AIAA-2010-0863, 48 ${ }^{\text {th }}$ AIAA ASM Conf., Orlando, FL, Jan. 4-7, 2010. 
16. Seele, R., Tewes, P., Woszidlo, R., McVeigh, M.A., Lucas, N.J., and Wygnanski, I.J., "Discrete Sweeping Jets as Tools for Improving the Performance of the V-22," J. of Aircraft, Vol. 46, No. 6, Nov.-Dec. 2009.

17. Coanda, Henri, "Device for Deflecting a Stream of Elastic Fluid Projected into an Elastic Fluid," United States Patent 2,052,869, Issued September 1, 1936.

18. Metral, A., "Sur un Phenomene de Deviation des Vienes Fluides et Ses Applications (Effect Coanda)," Proceedings of the $5^{\text {th }}$ International Congress for Applied Mechanics, Cambridge, MA, 1939.

19. Gokoglu, S.A., Kuczmarski, M.A., Culley, D.E., and Raghu, S., "Numerical Studies of a Fluidic Diverter for Flow Control," AIAA-2009-4012, 39 ${ }^{\text {th }}$ AIAA Fluid Dynamics Conf., San Antonio, TX, 22-25 June 2009, also NASA/TM-2009-216088.

20. Feikema, D. and Culley, D. "Computational Fluid Dynamic Modeling of a Fluidic Actuator for Flow Control," AIAA-2008-557, 46 ${ }^{\text {th }}$ AIAA Aerospace Sciences Meeting and Exhibit, January 7-10, 2008, Reno, NV.

21. Kelecy, F.J., "Coupling Momentum and Continuity Increases CFD Robustness," ANSYS Advantage, Vol. II, Issue 2, 2008, pp. 49-51.

22. Tesar, V., Hung, C.-H., and Zimmerman, W.B., "No-moving-part hybrid-synthetic jet actuator," Sensors and Actuators A, Vol. 125, 2006, pp. 159-169. 


\begin{tabular}{|c|c|c|}
\hline \multicolumn{2}{|c|}{ REPORT DOCUMENTATION PAGE } & $\begin{array}{l}\text { Form Approved } \\
\text { OMB No. 0704-0188 }\end{array}$ \\
\hline \multicolumn{3}{|c|}{$\begin{array}{l}\text { The public reporting burden for this collection of information is estimated to average } 1 \text { hour per response, including the time for reviewing instructions, searching existing data sources, gathering and maintaining the } \\
\text { data needed, and completing and reviewing the collection of information. Send comments regarding this burden estimate or any other aspect of this collection of information, including suggestions for reducing this } \\
\text { burden, to Department of Defense, Washington Headquarters Services, Directorate for Information Operations and Reports (0704-0188), } 21215 \text { Jefferson Davis Highway, Suite } 1224 \text {, Arlington, VA } 22222-24302 \text {. } \\
\text { Respondents should be aware that notwithstanding any other provision of law, no person shall be subject to any penalty for failing to comply with a collection of information if it does not display a currently valid OMB } \\
\text { control number. } \\
\text { PLEASE DO NOT RETURN YOUR FORM TO THE ABOVE ADDRESS. }\end{array}$} \\
\hline $\begin{array}{l}\text { 1. REPORT DATE (DD-MM-YYYY) } \\
01-10-2010\end{array}$ & $\begin{array}{l}\text { 2. REPORT TYPE } \\
\text { Technical Memorandum }\end{array}$ & 3. DATES COVERED (From - To) \\
\hline \multirow{3}{*}{\multicolumn{2}{|c|}{$\begin{array}{l}\text { 4. TITLE AND SUBTITLE } \\
\text { Numerical Studies of a Supersonic Fluidic Diverter Actuator for Flow Control }\end{array}$}} & 5a. CONTRACT NUMBER \\
\hline & & 5b. GRANT NUMBER \\
\hline & & 5c. PROGRAM ELEMENT NUMBER \\
\hline \multirow{3}{*}{\multicolumn{2}{|c|}{$\begin{array}{l}\text { 6. AUTHOR(S) } \\
\text { Gokoglu, Suleyman, A.; Kuczmarski, Maria, A.; Culley, Dennis, E.; Raghu, Surya }\end{array}$}} & 5d. PROJECT NUMBER \\
\hline & & 5e. TASK NUMBER \\
\hline & & $\begin{array}{l}\text { 5f. WORK UNIT NUMBER } \\
\text { WBS 561581.02.08.03.17.13.01 }\end{array}$ \\
\hline \multicolumn{2}{|c|}{$\begin{array}{l}\text { 7. PERFORMING ORGANIZATION NAME(S) AND ADDRESS(ES) } \\
\text { National Aeronautics and Space Administration } \\
\text { John H. Glenn Research Center at Lewis Field } \\
\text { Cleveland, Ohio 44135-3191 }\end{array}$} & $\begin{array}{l}\text { 8. PERFORMING ORGANIZATION } \\
\text { REPORT NUMBER } \\
\text { E-17437 }\end{array}$ \\
\hline \multirow{2}{*}{\multicolumn{2}{|c|}{$\begin{array}{l}\text { 9. SPONSORING/MONITORING AGENCY NAME(S) AND ADDRESS(ES) } \\
\text { National Aeronautics and Space Administration } \\
\text { Washington, DC 20546-0001 }\end{array}$}} & $\begin{array}{l}\text { 10. SPONSORING/MONITOR'S } \\
\text { ACRONYM(S) } \\
\text { NASA }\end{array}$ \\
\hline & & $\begin{array}{l}\text { 11. SPONSORING/MONITORING } \\
\text { REPORT NUMBER } \\
\text { NASA/TM-2010-216805 }\end{array}$ \\
\hline \multicolumn{3}{|c|}{$\begin{array}{l}\text { 12. DISTRIBUTION/AVAILABILITY STATEMENT } \\
\text { Unclassified-Unlimited } \\
\text { Subject Category: } 01 \\
\text { Available electronically at http://gltrs.grc.nasa.gov } \\
\text { This publication is available from the NASA Center for AeroSpace Information, 443-757-5802 }\end{array}$} \\
\hline
\end{tabular}

\section{SUPPLEMENTARY NOTES}

\section{ABSTRACT}

The analysis of the internal flow structure and performance of a specific fluidic diverter actuator, previously studied by time-dependent numerical computations for subsonic flow, is extended to include operation with supersonic actuator exit velocities. The understanding will aid in the development of fluidic diverters with minimum pressure losses and advanced designs of flow control actuators. The self-induced oscillatory behavior of the flow is successfully predicted and the calculated oscillation frequencies with respect to flow rate have excellent agreement with our experimental measurements. The oscillation frequency increases with Mach number, but its dependence on flow rate changes from subsonic to transonic to supersonic regimes. The delay time for the initiation of oscillations depends on the flow rate and the acoustic speed in the gaseous medium for subsonic flow, but is unaffected by the flow rate for supersonic conditions.

\section{SUBJECT TERMS}

Flow control; Fluidic actuators; Fluidic diverters; Numerical modeling; Supersonic flow control; Transonic flow control

\begin{tabular}{|c|c|c|c|c|c|}
\hline \multicolumn{3}{|c|}{ 16. SECURITY CLASSIFICATION OF: } & \multirow{2}{*}{$\begin{array}{l}\text { 17. LIMITATION OF } \\
\text { ABSTRACT } \\
\text { UU }\end{array}$} & \multirow{2}{*}{$\begin{array}{l}\text { 18. NUMBER } \\
\text { OF } \\
\text { PAGES } \\
25\end{array}$} & \multirow{2}{*}{$\begin{array}{l}\text { 19a. NAME OF RESPONSIBLE PERSON } \\
\text { STI Help Desk (email:help@sti.nasa.gov) } \\
\text { 19b. TELEPHONE NUMBER (include area code) } \\
\text { 443-757-5802 }\end{array}$} \\
\hline $\begin{array}{l}\text { a. REPORT } \\
\text { U }\end{array}$ & $\begin{array}{l}\text { b. ABSTRACT } \\
U\end{array}$ & $\begin{array}{l}\text { c. THIS } \\
\text { PAGE } \\
\text { U }\end{array}$ & & & \\
\hline
\end{tabular}



